\title{
Study on Combined Braking of Eddy Current Retarder and The Main Brake
}

\author{
Liu Wenguang*, He Ren, Lu Wei and Ke Tongtong
}

\author{
School of Automobile and Traffic Engineering, Jiangsu University, Zhenjiang 212013, Jiangsu, China
}

\begin{abstract}
Aiming at the main brake force distribution by using the proportional distribution and the braking force of eddy current retarder with shift, it affected the attachment of wheels on the ground. Through the establishment of vehicle dynamics, relationship of sliding rate with braking force and the eddy current retarder braking dynamics model, the controlled method was researched by relative value as control parameters to the sliding rate and the target rate at the front wheel brake sliding. The sliding rate of the front and rear wheels was compared. Its difference value was control parameter to adjust the eddy current retarder braking force, which do compensation for the rear wheel braking force. This control strategy is carried based on the simulation analysis in Matlab/Simulink. The analysis results show that this method can make full use of road adhesion and improve the braking force and the traffic safety.
\end{abstract}

Keywords: Brake distribution, Eddy current retarder, slip, united brake.

\section{INTRODUCTION}

As a Non-friction assistance brake, eddy current retarder had a large number of applications on larger vehicle. It realized the shunt of load from wheel brake. The problem of decline of brake performance was resolved. Eddy current retarder resulted from hot recession for overheating of the friction in wheel hub [1-5]. It enhanced the security of the vehicle equipped with eddy current retarder, which braking force had a difference with orthodox vehicle. Vehicles brake stability had changed because the braking force of retarder on rear wheel changes the braking force distribution [6-8]. When vehicle with eddy current retarder was in emergency braking condition, there would be an impact on the braking security. For the additional braking force from retarder, the ratio of braking force on rear wheel to total braking force increased, which increased the possibility of rear wheel lock in advance during the brake process. To avoid wheel lock during the brake process, ABS was used in vehicle to improve directional stability and steering ability, which let vehicle make full use of the road adhesion coefficient and reduced braking distance. Because of the difference of the road adhesion coefficient $\varphi$ and fixed distribution coefficient of braking force, it was difficult to realize the wheel lock at the same time. So the braking force of retarder was used to maintain harmony between front and rear wheel braking force. Now a days step shift brake is being used in eddy current retarder, which influences brake stability, driving safety and passenger comfort. Due to the sudden change of braking torque, braking shock is caused. In this article, pulse width modulation technique was used to solve the problem of continuous current adjustment of eddy current

*Address correspondence to this author at the School of Automobile and Traffic Engineering, Jiangsu University, Zhenjiang 212013, Jiangsu, China; E-mail: 719795343@qq.com retarder. Front and rear wheel locked at the same time could be realized by adjusting the braking torque of retarder. PWM technique used the conduction and close of semiconductor switching devices to control the voltage pulse width and cycle [9], which realized variable voltage. PWM technique could be used to control the working current of the field winding, because it could be restraining harmonic effectively and has a good dynamic response. Therefore, finding how to control the braking torque of eddy current retarder and realizing front and rear wheel lock at the same time, is the main propose of this study.

\section{BRAKING TORQUE ANALYSIS OF EDDY CUR- RENT RETARDER}

Retarder was made up of stator, rotor, fixed mount and so on. High guiding magnetic material cored on the stator distribute in a circle. The field coils of retarder were excited by adjusted direct current to generate the magnetic field, which forms a circuit between the stator pole, air gap and the rotor disc $[10,11]$. The rotor disc rotates in the magnetic field generated from the field coils. Retarder changed the suction of coils by current change to realize braking. The size of braking torque depended on structure parameter of the retarder, rotation speed of the rotor disc and exciting current $[5,8]$. Retarder braking torque formula:

$$
\begin{aligned}
& T=\frac{\left(N_{p} \mu_{0} \rho\right)^{1.5}}{2 \sqrt{\mu_{r}} \arcsin \left(\frac{d}{2 R_{l}}\right)} \\
& \times \frac{\left(\pi d^{2} N I\right)^{2} \sqrt{2 w}}{\left(16 I_{g} \rho+\frac{k_{e} d^{2}}{2} \sqrt{\frac{\rho N_{p} w \mu_{0}}{\mu_{r}}}\right)^{2}}
\end{aligned}
$$




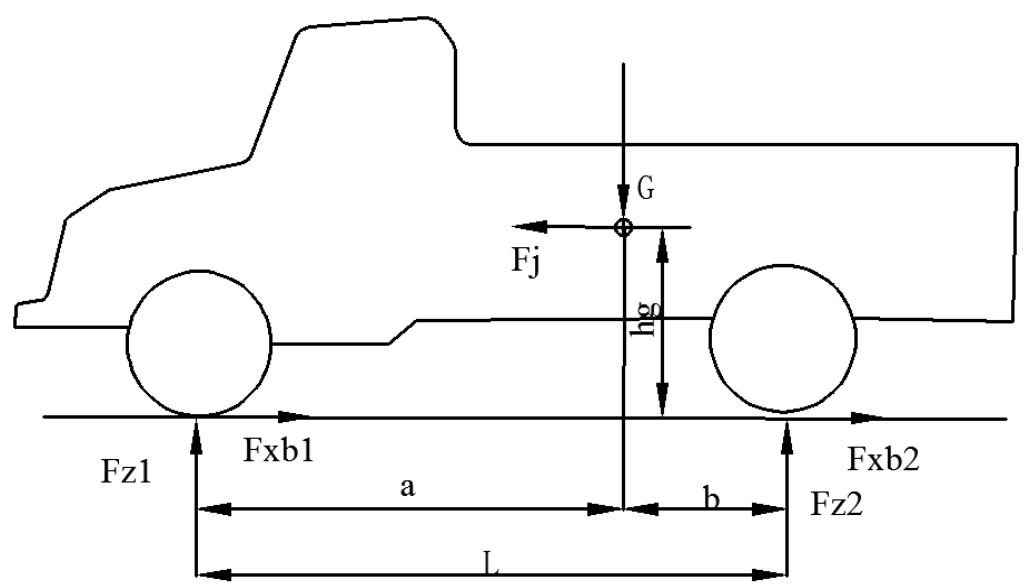

Fig. (1). Schematic diagram of vehicle brake.

In the formula,

$N_{p} \longrightarrow$ number of pole pairs

$\mu_{0} \longrightarrow$ air permeability

$\rho$ - the rotor disc resistivity $(\Omega \cdot m)$

$d-$ core diameter

$N$ - turns per coil

$I-$ exciting current (A)

$w$ _ rotation speed of the rotor $\operatorname{disc}(\mathrm{rad} / \mathrm{s})$

$\mu_{r} \longrightarrow$ relative permeability of the rotor disc

$I_{g} \longrightarrow \operatorname{air} \operatorname{gap}(\mathrm{m})$

$R_{l} \longrightarrow$ center radius of the magnet exciting coil(m)

$k_{e} \_$convert coefficient, usually value 1.5 .

\section{FORCE ANALYSIS OF VEHICLE BRAKING}

\subsection{Wheel Force of Vehicle Braking}

The braking force of the vehicle $F_{X b}$ was the external force slowing down the vehicle to still. The braking force depended on the braking force of the main brake when it is less than road braking force. It was limited by the ground adhesion conditions meanwhile. Sufficient braking force to vehicle was achieved with sufficient braking force of the main brake and sufficient adhesive force $F_{\varphi}$ which was from the ground. The formula was as follows.

$F_{X b}=\varphi_{b} F_{Z} \leq F_{\varphi}=\varphi F_{Z}$

In the formula,

$\varphi_{b} \longrightarrow$ braking force coefficient

$\varphi \_$road adhesion coefficient
$F_{Z} \longrightarrow$ the front and rear wheels counterforce

\subsection{Relationship of Braking Force Coefficient with Slid- ing Rate}

Braking force coefficient had something to do with sliding rate, rolling part of the wheel decreases and the sliding part increases with the increase of the intensity of the brake, the formula of sliding rate was as follows:

$s=\frac{v-r \omega}{v} \times 100 \%$

With different sliding rates, braking force value was different. Double linear model represents the relationship of longitudinal adhesion coefficient between wheel, ground and sliding rate [12], its function could be expressed as:

$\varphi_{b}=\left\{\begin{array}{c}\varphi_{p} \frac{s}{s_{p}}, 0 \leq s \leq s_{p} \\ \varphi_{s}+\frac{(1-s)\left(\varphi_{p}-\varphi_{s}\right)}{1-s_{p}}, s_{p}<s \leq 1\end{array}\right.$

In the formula,

$\varphi_{p} \_$the peak of adhesion coefficient

$\varphi_{s} \_$sliding adhesion coefficient

$s_{p} \_$the peak of adhesion coefficient

\subsection{The Dynamic Model Vehicle Braking System}

When the vehicle was running, it suffered from the air resistance and tire rolling resistance. In order to study conveniently, the influence of air resistance, tire rolling resistance and tire lateral force impacting the vehicle braking, were ignored. Only the tire longitudinal force influence the brake of the vehicle, was considered. So, the stress situation of vehicle braking on the level road is shown in Fig. (1). 
It ignored vehicle rolling resistance torque, the air resistance and inertia torque produced by rotation quality deceleration in Fig. (1). The wheel counterforce was:

$$
\begin{aligned}
& F_{Z 1}=\left(G b+m \frac{d u}{d t}\right) / L \\
& F_{Z 2}=\left(G a-m \frac{d u}{d t}\right) / L
\end{aligned}
$$

In the formula, $F_{Z 1}$ and $F_{Z 2}$ were respectively the front and rear wheels counterforce. $G$ was the vehicle gravity. $b$ was the centroid to the rear axle center line distance. $a$ was the centroid to the front axle center line distance. $m$ was the vehicle mass. $\frac{d u}{d t}$ was the vehicle deceleration. $L$ was distance between vehicle shaft. $L=a+b$

According to Fig. (1), the front and rear wheels at the same time locking conditions are shown in equation 4,5 .

$$
\begin{aligned}
& \left\{\begin{array}{l}
F_{\mu f}+F_{\mu r}=\varphi m g \\
\frac{F_{\mu f}}{F_{\mu r}}=\frac{b+\varphi h_{g}}{a-\varphi h_{g}}
\end{array}\right. \\
& \left\{\begin{array}{l}
F_{\mu f}=\varphi \frac{m g}{(a+b)}\left(b+\varphi h_{g}\right) \varphi \\
F_{\mu r}=\varphi \frac{m g}{(a+b)}\left(a-\varphi h_{g}\right) \varphi
\end{array}\right.
\end{aligned}
$$

In the formula, $F_{\mu f}, F_{\mu r}$ were respectively the front and rear wheel braking force. $a$ was the distance from center of mass to front axle. $b$ was the distance from center of mass to rear axle rear axle. $h_{g}$ was the height from center of mass.

For single wheel model, we assumed that quality of the wheel was $m_{w}$, rotational inertia of the wheel was $I_{w}$, angular velocity of rotation of the wheel was $\omega$. Regardless of the influence of air resistance and rolling resistance, differential equation formula of the wheel was:

$I_{w} \frac{d \omega}{d t}=F_{X b} r-T_{\mu}$

Braking force for the rear wheel should be the total force of the main braking force and braking force of eddy current retarder braking force. Formula for braking force for the rear wheel is:

$$
F_{\mu 2}=\frac{1-\beta}{\beta} F_{\mu 1}+F_{r}
$$

In the formula, $\beta$ was for the front and rear wheel braking force distribution coefficient. $F_{r}$ was the eddy current retarder braking force.

\section{CONTROL STRATEGY ANALYSIS OF COM- BINED EDDY CURRENT RETARDER AND THE MAIN BRAKE}

Because the road adhesion coefficient $\varphi$ was different, the braking force distribution of front and rear wheels at the same time lock was different. In order to eliminate the influence of road adhesion coefficient $\varphi$, the parameter $\varphi$ in the formula was to eliminate. The distribution curve of the ideal braking force of the front and rear wheel brake was gained. That is,

$$
\frac{h_{g}}{\beta} \varphi^{2}-\left(a-\frac{1-\beta}{\beta} b\right) \varphi+\frac{(a+b) F_{r}}{m g}=0
$$

In order to ensure directional stability and enough brake efficiency when the vehicle brakes, ECER13 regulation put forward clear requirements for the braking force of front and rear wheel in double-axle vehicles. It specified that the adhesion coefficient curve of front axle should be above the rear axle. For various kinds of vehicles during road adhesion coefficient was in scope $\varphi=0.2 \sim 0.8$, it required braking intensity value in the scope of $z \geq 0.1+0.85(\varphi-0.2)$. For the trucks whose gross mass was more than $3.5 \mathrm{t}$, when braking intensity is $z=0.15 \sim 0.3$, the adhesion coefficient curve of each shaft was between two parallel lines $\varphi=z \pm 0.8$ that was equal to the ideal adhesion coefficient line. When braking intensity is $z \geq 0.3$, the adhesion coefficient curve of rear axle met $z \geq 0.3+0.74(\varphi-0.38)$. The braking force distribution curve is illustrated in Fig. (2).

In order to make better use of the road adhesion coefficient and ensure the front wheel control without losing the steering stability in the braking force distribution. Using the front wheel as the control target with front wheel attachment rate reached the maximum road adhesion coefficient as the control target. At the same time use different sliding rate value of the front and rear wheel to control braking force of eddy current retarder. The method using the front and rear wheels slip rate as control parameter to control eddy current retard input current and quickly adjust braking force value of the rear wheel, achieved the purpose of controlling the rear wheel braking force. The flow chart is shown in Fig. (3).

\section{ANALYSIS OF RESULTS}

According to the formula derived in front, a simulation model of vehicle braking force was constructed to verify the algorithm under the environment of Matlab/Simulink. The comparison of two kinds of methods of sliding rate control simulation was done. The simulation results are shown in Fig. (4).

As you can see from Fig. (4), for vehicles equipped with combined eddy current retarder and the main brake, the speed decreases faster as the braking force increased. Fig. (5) illustrates brake input current change of eddy current retarder when rear wheel brakes. Output current is automatically adjusted to the eddy current retarder sliding rate. It controls 


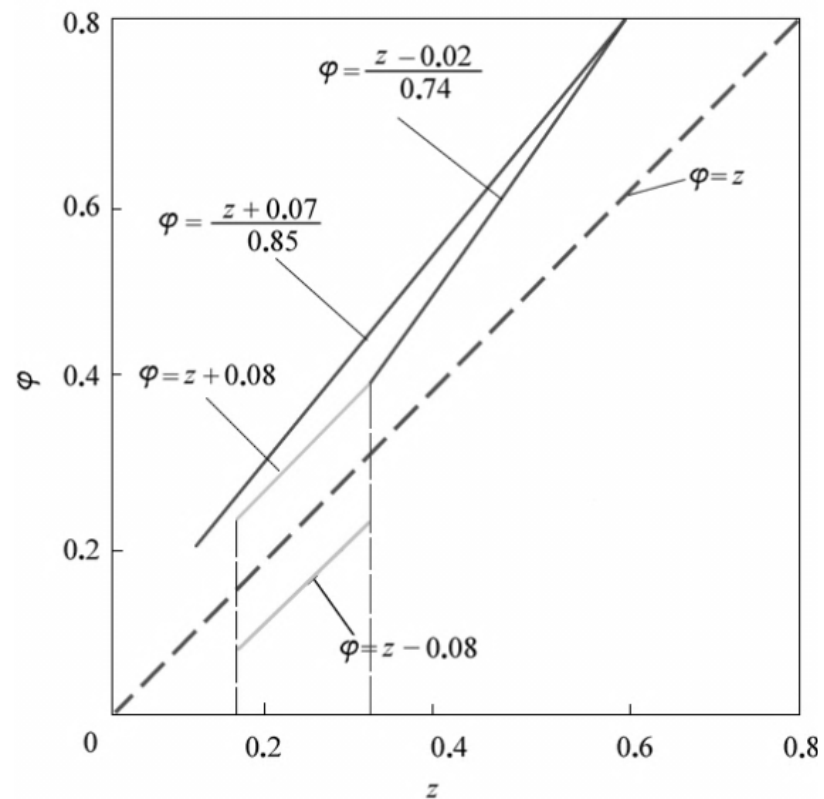

Fig. (2). The truck braking force distribution diagram of ECE regulation.

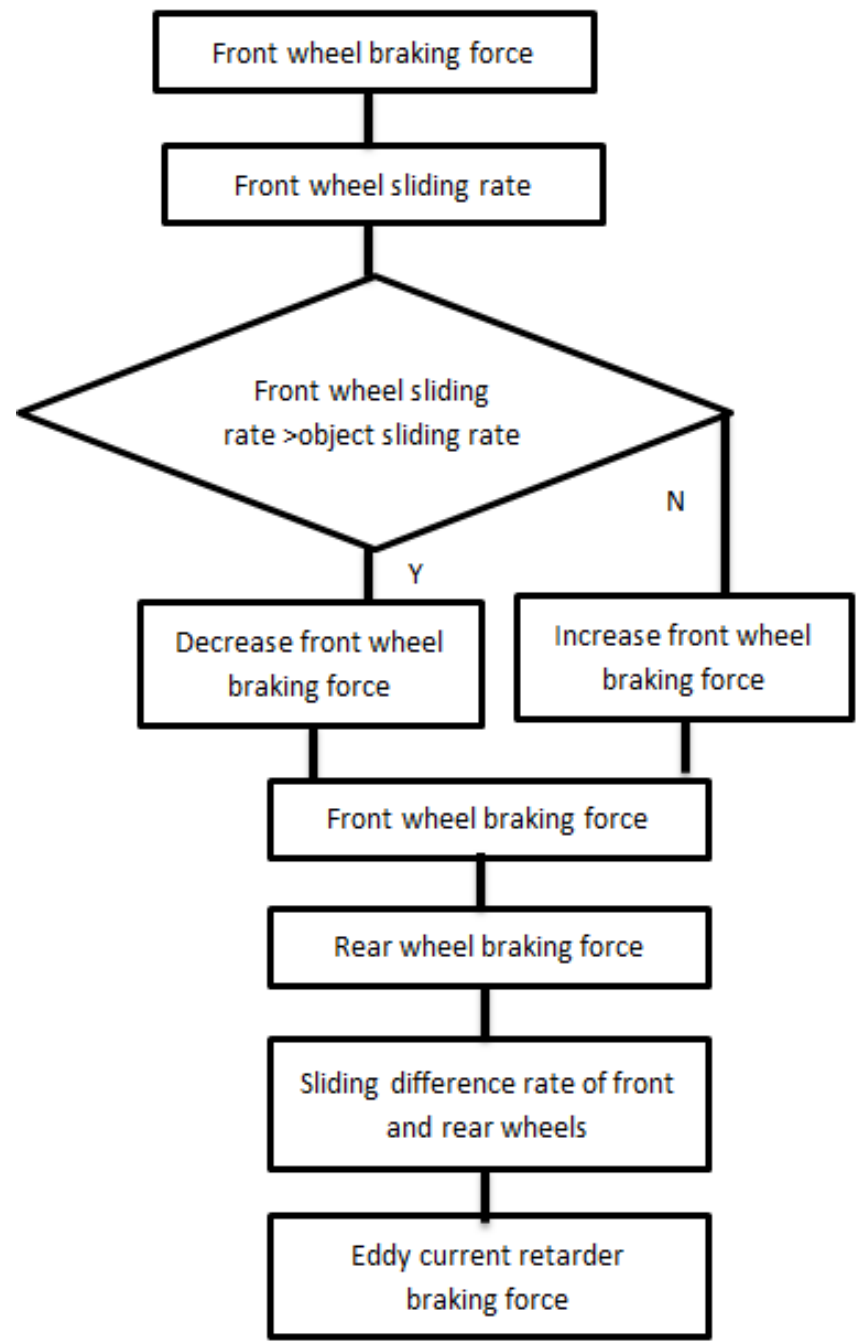

Fig. (3). Control chart. 


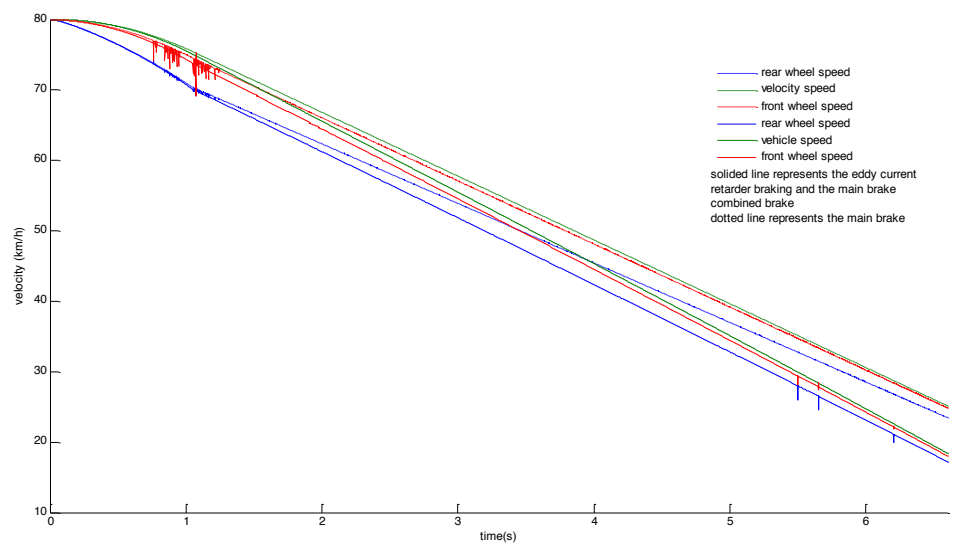

Fig. (4). Curves of brake.

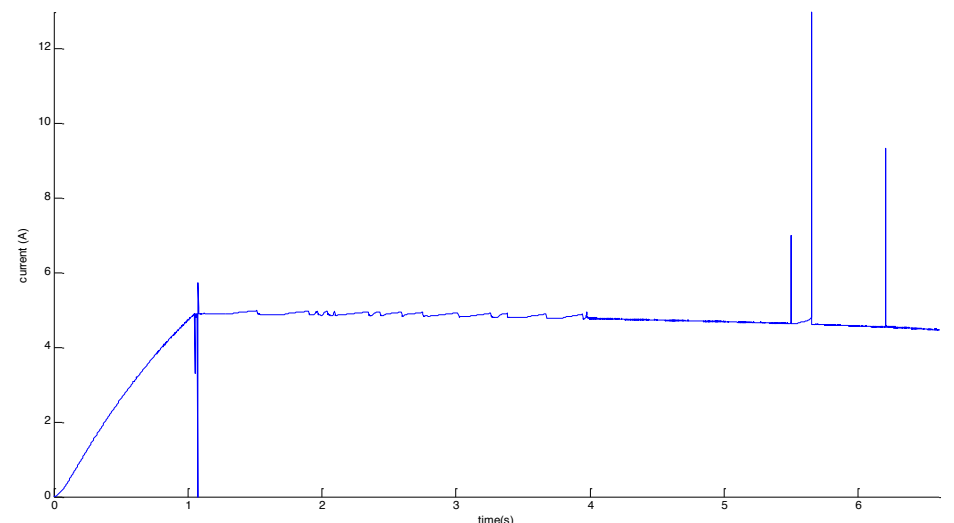

Fig. (5). Curves of current of eddy current retarder.

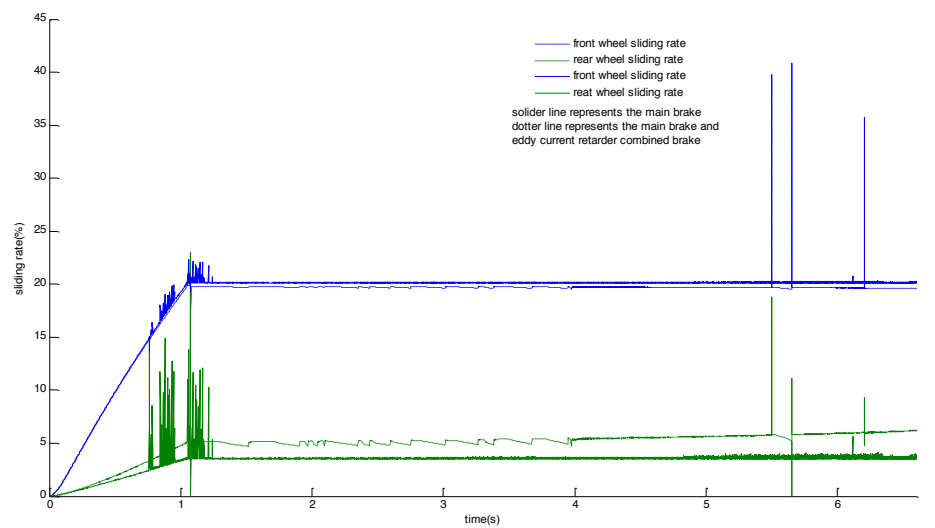

Fig. (6). Curves of sliding rate.

braking torque of eddy current retarder. There is a problem of eddy current retarder shown in Fig. (5), in which the current slows down the growth rate. In Fig. (6) the rear wheel sliding rate changes due to the increase in braking force of eddy current retarder, the sliding rate is closer to the optimal sliding rate. The front and rear wheels sliding rate relative value is small. The braking force of eddy current retarder is increased, which increases the rear wheel braking force. It can increase the rear wheel ground attachment, velocity and wheel angular velocity of the vehicle and wheel fell faster, shorter braking distance, and improve the traffic safety.

\section{RESULT}

The braking force distribution comprised of a combination of brake of eddy current retarder braking system and the 
main brake system is researched. Relative value of the sliding rate and the target rate at the front brake wheel is taken as a control parameter. At the same time sliding rate of the front and rear wheel is compared. The difference of sliding rate of front and rear brake wheel is controlled to adjust the eddy current retarder braking force compensation rear wheel braking power. Input current to eddy current retarder increase can enhance the rear wheel braking force. This method has a problem with eddy current retarder that the current slows down growth rate. This control method makes sure that the rear wheel can make full use of the road adhesion coefficient. It increases the braking torque of the rear wheel and shortens braking distance, thereby improving the traffic safety.

\section{CONFLICT OF INTEREST}

The author confirms that this article content has no conflicts of interest

\section{ACKNOWLEDGEMENTS}

This work was supported in part by a grant from the Jiangsu Provincial Science and Technology Achievement Transformation Funds(BA2010050), Key Laboratory of Jiangsu Province Automobile Open Fund(QC201003)and Project supported by the Jiangsu University Foundation(11JDG077).

\section{REFERENCES}

[1] S. Anwar, and R.C. Stevenson, "Torque characteristics analysis of an eddy current electric machine for automotive braking applica- tions," In: Proceedings of the 2006 American Control Conference, 2006, pp. 3996-4001.

[2] S. Anwar, "A parametric model of an eddy current electric machine for automotive braking application", IEEE Transactions on Control System Technology, vol. 12, no. 3, pp. 422-427, 2004.

[3] Z. Yingsheng, H. Ren, and W. Yongtao, "Fuzzy distribution of braking forces in united braking system of downhill automobile at constant speed", China Mechanical Engineering, vol. 19, no. 8, pp. 1003-1007, 2008.

[4] M. Jian, C. Yinsan, and Y. Qiang, "Evaluation of retarder to automobile braking stability", Journal of Traffic and Transportation Engineering. vol. 2, no. 1, pp.105-108, 2002.

[5] H. Ren, W. Yongtao, and Z. Yingsheng, "Simulation research on brake stability of united brake system of buses", Journal of System Simulation. vol. 21, no. 8, pp. 2156-2159, 2009.

[6] Z. Yan, L. Chengye, and H. Ren, "Influence of eddy current retarder on vehicle braking force utilization", Journal of Traffic and Transportation Engineering, vol. 11, no. 6, pp. 62-67, 2011

[7] Z. Yingsheng, H. Ren, and W. Yongtao, "Analysis on influence of eddy current retarder on braking stability of vehicle", Transactions of the Chinese Society for Agricultural Machinery, vol. 38, no. 9, pp.16-18, 2007.

[8] H. Ren, W. Yongtao, and Z. Yingsheng. "Performance simulation analysis of the united brake system of automobiles", Acta ArmamentaII, vol. 28, no. 10, pp. 1153-1158, 2007.

[9] H. Ren, Z. Yingsheng and W. Yongtao. "Real-time control of braking torque of eddy-current retarder", Journal of Jiangsu University (Natural Science Edition), vol. 29, no. 3, pp. 202-205, 2008.

[10] H. Ren, Y. Fengyan, and H. Jianqing, "A computation method for braking torque of eddy current retarder", Automotive Engineering, vol. 26, no. 2, pp. 197-200, 2004.

[11] W. Sun, Y. Zhang, and B. Wu, "A new calculation method of brake torque for eddy current retarder”, Modern Machinery no. 4, pp. 2122, 2005.

[12] Y.W. Guang, L. Guo, and Y. Datai, "Study on fuzzy PID control algorithm for antilock brake system", Journal of Highway and Transportation Research and Development, vol. 21, no. 7, pp. 123126, 2004.

Received: September 22, 2014

(C) Wenguang et al.; Licensee Bentham Open.

This is an open access article licensed under the terms of the Creative Commons Attribution Non-Commercial License (http://creativecommons.org/licenses/by-nc/4.0/) which permits unrestricted, non-commercial use, distribution and reproduction in any medium, provided the work is properly cited. 